\title{
Work in Progress - An Undergraduate B-Learning Experience for the Teaching of Politics of Telecommunications and Information Society
}

\author{
Antonio Perez Yuste, Rafael Herradón Diez, Juan Blanco Cotano, José A. Sánchez Fernández \\ EUIT de Telecomunicación, Universidad Politécnica de Madrid, antonio.perez@upm.es, rafael.herradon@upm.es, \\ juan.blanco@upm.es, j.sanchez@upm.es
}

\begin{abstract}
The Telecommunications Act of 1998, approved by the Spanish House of Representatives, set up the beginning of the telecommunications market liberalization process in Spain and the establishment of a new economic and social model based on the Information Society Paradigm, as already highlighted by the European Commission in 1993. Taking advantage of the necessity for undergraduate students to have a subject related to this matter, a new course on Politics of Telecommunications and Information Society was initially designed by a group of five professors from the Technical University of Madrid, four of which still maintain the project alive after eight years. The resulting course is teaching at the Technical University of Madrid since 1999. The course was initially conceived as an e-learning initiative based on the well-known Moodle Learning Management System and it comprises the next four lessons: Information Society, Telecommunications Regulation in Spain, Telecommunication Standardization and Certification and, e-Commerce \& Internet Security.
\end{abstract}

Index Terms - Distance Learning, ECTS, Moodle Learning Management System, Politics of Telecommunication.

\section{INTRODUCTION}

The liberalization of telecommunications, which was started in Spain in 1998, set up a new economic and social model based on the Information Society Paradigm [1]. That was the reason why a new course on Politics on Telecommunications and Information Society was incorporated in the undergraduate curriculum of the School of Telecommunications at Technical University of Madrid. The resulting course is offered since 1999 as an elective subject, being intended for undergraduate students in any year within their schooling program. The course was initially conceived as a distance learning program based on the well-known Moodle Learning Management System with a number of study units amounting to 4 ECTS (European Credit Transfer System). The WIP report will comprise the web-type resources used in Moodle, including the assignments of the course and the assessment carried out.
The current project status will be described and the academic results obtained by the students will be presented.

\section{COURSE Goals}

When this course was planned, three different objectives were mainly considered to be covered: first of all, it was expected the students obtain a knowledge related to Politics, Regulation and Information Society in a telecommunications context. As a second goal, it was considered to use a teaching methodology based on a distance learning approach, as it is a fact that courses can already be offered online with quality, scale and breadth [2][3]. And as a final goal, it was intended to complete the students' learning program by means of some compulsory lectures that required their presence in class in order to monitor their understanding and improve their progress.

\section{RESOURCES IN USE}

In order to achieve a distance learning approach, the course was organized with the support of the well-known Moodle Learning Management System (LMS). Moodle has demonstrated to be one of the most suitable open source platforms for e-learning and b-learning purposes [4], so that was the reason why it was selected from the first. By using this platform, a wide range of study resources were arranged (Slide Shows, Videos or HTML and PDF Files concerning legislation, regulation, standards and news) by using a structure based on four lessons: Information Society, Telecommunications Regulation in Spain, Telecommunication Standardization and Certification, and e-Commerce \& Internet Security. Every lesson has been conceived with a very similar scheme. First, each one includes several webtype resources to introduce students both to theoretical and practical issues besides some self-assessment quizzes for testing whether their progress has been suitable or need, on the other hand, some improvements. The active participation of students by means of online discussion forums is also required, as well as the development of individual assignments from technical documents and specific information available in Internet. Furthermore, the students must also attend some lectures given by personnel staff belonging to Public Administration or private companies, specially invited for this purpose. These lectures are

October $22-25,2008$, Saratoga Springs, NY 


\section{Session T4E}

broadcasted through live video streaming in Internet and later uploaded in the course platform as one more resource.

\section{Teaching Methodology}

In the first, the subject matter of the course was taught by means of an e-learning methodology, but later it was fairly clear that the adoption of a blended learning (b-learning) methodology should improve the academic progress of the students. So, several activities were designed and included to fulfil the established course requirements. Among them, it can be cited: tutorials, cooperative workgroups and mandatory attendance to lectures. The development of the course is described next:

- The course schedule is established every year and published in Moodle, remarking activities, lectures, discussion forums, self-assessment quizzes and evaluation deadlines, as shown in Figure 1.

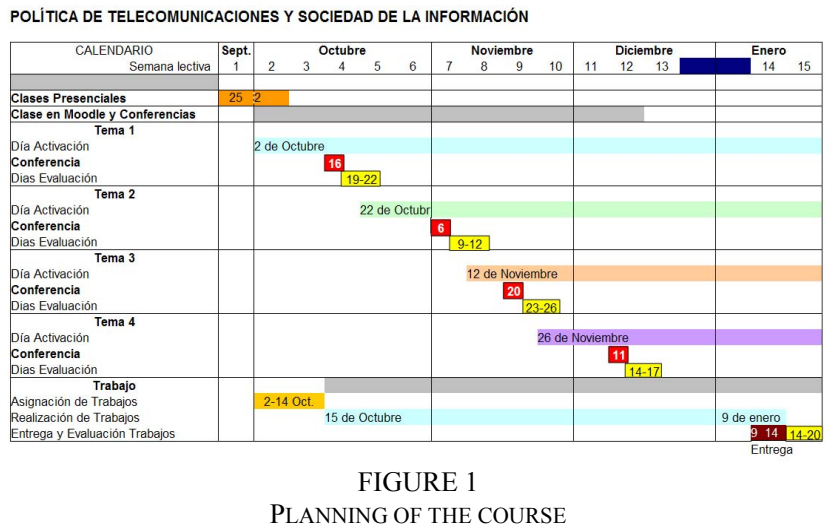

- Every unit of study is introduced with a briefing and contextual lecture, which is followed by different supporting documents, some self-assessment quizzes, a discussion forum and the final assessment of the unit (see Figure 2). Furthermore, every unit also comprises an online video streaming with the keynote speech given by the aforesaid specialized person.

- The development of distance learning resources and the monitoring of the academic progress of the students is controlled by professors through the Moodle platform, with a continuous evaluation of the assignments carried out.

\section{EVALUATION AND RESUlts}

The final results shows a course pass rate next to $90 \%$ of students. During last years, it has been checked that assignments to be carried out in workgroups at-home gave poor quality results. However, when these assignments were individually carried out and the evaluation was done by using assessment templates and rubric templates, the general results were clearly improved. An end-of-course survey is administered to the students in order to know their opinion, including different types of questions about teaching and methodological topics, evaluation procedures, technical aspects of the platform and motivation obtained. The result shows an average level of satisfaction of 77.25 points out of
100. In addition, the relevant issues considered by the students have been: the approach done to politics, regulation, standardization and certification in the framework of Telecommunications, the attendance to lectures, as well as the possibility of learning the subject matter of the course through Internet, whereas the difficulty of keeping a communication with teachers and classmates as well as the continuous evaluation applied, were considered as negative factors.

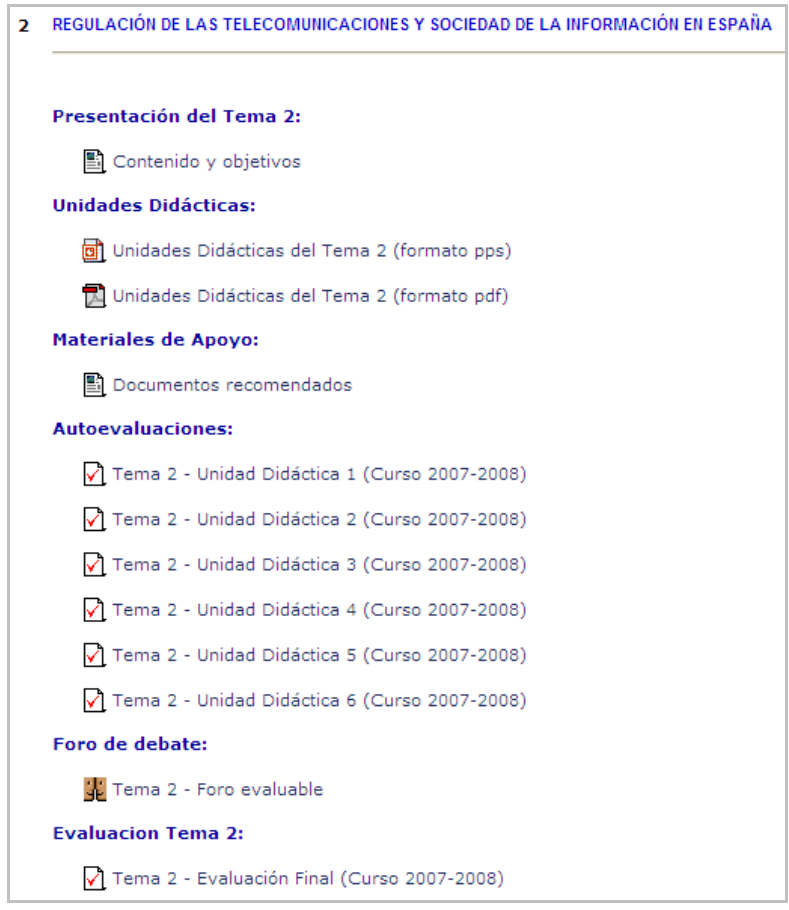

FIGURE 2

ONE OF THE UNITS OF STUDY

\section{CONClusions}

We can conclude that the results of this experience have been very positive: from the development of new learning methodologies and the use of new information and communication technologies, to the final academic results obtained and the level of satisfaction of the students achieved. The use of Moodle, together with a blended learning methodology, has proved to be very suitable in the development of specific courses for engineering students.

\section{REFERENCES}

[1] Larouche, P, "Competition Law and Regulation in European Telecommunications", Ed. Hart Publishing, Oxford, 2000.

[2] Bourne, J., Harris, D., Mayadas, F., "Online Engineering Education: Learning Anywhere, Anytime", Journal on Engineering. Education, vol. 94, no. 1, Jan. 2005, pp. 131-146.

[3] Bates, A. W., "Technology, E-Learning and Distance Education", Ed. Routledge, London, 2005.

[4] Graf, S., List, B., "An Evaluation of Open Source E-Learning Platforms Stressing Adaptation Issues", The $5^{\text {th }}$ IEEE International Conference on Advance Learning Technologies, Kaohsiung, Taiwan, 5-8 July 2005, pp. 163-165.

October 22 - 25, 2008, Saratoga Springs, NY $38^{\text {th }}$ ASEE/IEEE Frontiers in Education Conference 